\title{
The Implementation of Animal Assisted Therapy Programs in Substance use Disorders
}

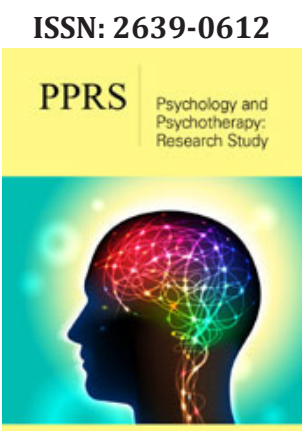

*Corresponding author: Baquero A, Amigó Castellón Project, Spain

Submission: 侮 July 24, 2020

Published: 想 August 04, 2020

Volume 4 - Issue 1

How to cite this article: Baquero A, Robledillo J, Monfort M. The Implementation of Animal Assisted Therapy Programs in Substance use Disorders. Psychol Psychother Res Stud. 4(1). PPRS. 000577. 2020.

DOI: 10.31031/PPRS.2020.04.000577

Copyright@ Baquero A, This article is distributed under the terms of the Creative Commons Attribution 4.0 International License, which permits unrestricted use and redistribution provided that the original author and source are credited.

\author{
Baquero $\mathbf{A}^{1,2,3 *}$, Robledillo J ${ }^{1}$ and Monfort $\mathbf{M}^{1,3}$ \\ ${ }^{1}$ Amigó Castello Project, Spain \\ ${ }^{2}$ Department of medicine, CEU Cardenal Herrera, Spain \\ ${ }^{3}$ TXP Research Group, Medicine department, CEU Cardenal Herrera University, Spain
}

\begin{abstract}
Animal Assisted Therapy (AAT) is presented as a complementary program that, together with rehabilitation treatment, favors the clinical evolution of the patients who participate in it. The integration of AAT in the healthcare and health field has been increased in recent years; highlighting the growing interest in AAT programs, along with numerous studies that examine the benefits and efficacy of different therapeutic approaches with animals [1,2], after different and novel pilot experiences in substance use disorders [3], it seems that TAA is an intervention approach with utility in the rehabilitation processes of people with disorder substance use.
\end{abstract}

Keywords: Animal assisted therapy; Substance use disorders; Motivation; Therapeutic intervention

\section{Introduction}

AAT is a coordinated, programmed and structured therapeutic intervention, where the collaboration of an animal with specific qualities is included, as a characteristic element of the rehabilitation process. All the treatment must be designed, documented and evaluated by the personnel who carry out the program, together with the professionals of the resource in which it is applied [4-6]. The AAT differs from other animal activities (animal assisted activities, service animal programs and animal assisted education), primarily because the process of intervention of the animal and responsible specialist is supervised and subject to the action of the reference professional that includes such therapy within the rehabilitation treatment [4]. In recent years, the scientific community has been making an important effort to show how the use of animals in clinical intervention processes helps improve the physical, psychological and social health of patients. AAT is presented as adjunctive therapy to standard therapeutic programs, contributing, in a supplementary way, to achieving the objectives proposed in the treatment $[6,7]$.

\section{AAT Benefits}

The performance of AAT programs are included within joint therapies that enhance the benefits achieved by the patient by participating in standard rehabilitation programs $[8,9]$. This is because interactions with the animal stimulate the release of oxytocin, improving patients' perceived mental health, behavior, therapeutic intervention and, finally, the relationship of well-being with the professionals of the resource $[3,6]$. In AAT the animal is integrated into psychotherapeutic treatment with the aim of promoting the increase of the physical, psychosocial and cognitive functions of the patients. The benefits provided are summarized in the following areas: identification and affective regulation (emotions, mood and motivation); achieving healthy self-esteem; social skills learning; improvement of the socialization process; and lastly, the stimulation of cognitive functions [3,5]. The benefits provided can be used in many healthcare and healthcare settings, favoring patients with various pathologies. Table 1 shows the main animals used as co-therapists in rehabilitation programs, along with the diversity of psychotherapeutic intervention settings where TAA programs are implemented [1]. 
Table 1: Animal species and areas of AAT intervention.

\begin{tabular}{|c|l|}
\hline \multicolumn{2}{|c|}{ AAT } \\
\hline Main animals used & Horses, dolphins, farm animals (cows, donkeys, goats, sheep, chickens, pigs, rabbits, ducks ...), cats, dogs and pets. \\
\hline Different areas of intervention & Neurorehabilitation, education, mental health, geriatrics, gerontology, prisons, hospitals, addictions and oncology. \\
\hline
\end{tabular}

Source. Own elaboration

\section{AAT}

Main animals used Horses, dolphins, farm animals (cows, donkeys, goats, sheep, chickens, pigs, rabbits, ducks ...), cats, dogs and pets. Different areas of intervention Neurorehabilitation, education, mental health, geriatrics, gerontology, prisons, hospitals, addictions and oncology.

\section{Implementation of AAT in substance use disorders}

Once the benefits of incorporating TAA are known, the possible utility in the framework of rehabilitation in addictions is raised; where TAA programs complementary to the treatment program are temporarily integrated, mainly with the collaboration of therapy dogs, which participated as therapeutic tool [2]. The sessions usually are structured following a standard scheme: it began with an introduction in which the animal therapy technician begins the topic and objectives pursued in the session, and the patients participate in observation activities to learn the handling of the animal [8]. After this section, patients actively experiment and interact with the animal, working on the objectives set. Finally, it concludes with the evaluation of the participants accompanied by the therapist and the specialist in charge to assess the achievements obtained [5].

In the course of the successive evaluations, an improvement is sought in the therapeutic alliance with the professionals who are part of the therapeutic team of the resource; greater adherence to treatment, with the aim of increasing the motivation of patients who interacted with the animal $[3,9]$. Other perceived benefits, and no less important, should be presented, such as: the feeling of psychological well-being linked to a better management of anxiety, anxiety or craving, since interaction with the animal facilitates the identification and regulation of the present emotional state [2,7]. Finally, a second group of benefits is detected, which includes the improvement of perceived social support, the learning of coping strategies and the best adaptation to the residential resource $[3,8]$.

\section{Conclusion}

It is valued that the implementation of AAT, as a complement to the therapy given in addiction rehabilitation centers, can be beneficial, since it favors the motivation, participation and involvement of patients [10]. AAT facilitates a proactive attitude in the patient, which as it acquires new benefits during the course of the sessions using interaction with the animal, manages to improve adherence to treatment, facilitates the therapeutic relationship, and ultimately, is a multisensory element of intervention that favors the evolution and achievement of psychotherapeutic treatment goals [2,11]. Thus, the need to continue intervening in this line is considered, in order to scientifically study the usefulness and validity of AAT as a therapeutic complement to the treatment of substance use disorders and behavioral addictions.

\section{References}

1. Mauriño GPA, Luz AL, Babot M, Lacasa F, Álvarez Segura M (2017) La aplicación de la terapia asistida con animales en la salud mental infartojuvenil. Revista de Psicología Universidad de Antioquia 9(2): 177-188.

2. Casey J, Csiernik R, Knezevic D, Ebear J (2018) The impact of animalassisted intervention on staff in a seniors residential care facility. International Journal of Mental Health and Addiction 16(5): 1238-1248.

3. Montolio MM, Sancho Pelluz J (2019) Animal assisted therapy in the residential treatment of dual pathology. International Journal of Environmental Research and Public Health 17(1): 120.

4. Huertas MC, Nieves ICR, Álvarez M (2014) Desarrollo de la terapia asistida por animales en la psicología. Informes Psicológicos 14(2): 125144.

5. Rubio RD, Loscertales AA, Obís MMB, Obís PB, López APS (2017) Terapia asistida por animales. Animal-supported therapy. Revista Española de Comunicación en Salud 8(2): 254-271.

6. Uhlmann C, Nauss C, Worbs A, Pfund U, Schmid P (2019) Effects of an animal-assisted intervention on psychiatric in-patient addiction treatment-a pilot study. Fortschr Neurol Psychiatr 87(5): 305-311.

7. Abreu T, Figueiredo AR (2015) Paws for help: Animal-assisted therapy. European Psychiatry 30(1): 1651.

8. Álvarez AA, Tobio TG, Roca VO, Facal VCA, Moldes VI, et al. (2013) Efectos de la terapia asistida con animales en personas con daño cerebral o lesión medular. Trauma (Spain) 24(2): 109-116.

9. Contalbrigo L, De Santis M, Toson M, Montanaro M, Farina L, et al. (2017) The efficacy of dog assisted therapy in detained drug users: A pilot study in an Italian attenuated custody institute. Int J Environ Res Public Health 14(7): 683-699.

10. Klemetsen MG, Lindstrom TC (2017) Animal-assisted therapy in the treatment of substance use disorders: A systematic mixed methods review. Human-Animal Interaction Bulletin 5(2): 90-117.

11. Duque CM, Lozano CA, Castro RH, Marín CA (2019) Educación asistida con perros. Inclusión \& Desarrollo 6(2): 15-23.

For possible submissions Click below:

Submit Article 